\title{
Effect of Internal Carotid Artery Aberrations on the Distance Between Styloid Process and Carotid Artery
}

\author{
Efecto de las Variaciones de la Arteria Carótida Interna en \\ la Distancia entre el Proceso Estiloides y la Arteria Carótida
}

K. Esen1; Y. Balci'; A. Ozgur ${ }^{1}$; S. Erdogan ${ }^{2} \&$ B. Ten ${ }^{1}$

\begin{abstract}
ESEN, K.; BALCI, Y.; OZGUR, A.; ERDOGAN, S. \& TEN, B. Effect of internal carotid artery aberrations on the distance between styloid process and carotid artery. Int. J. Morphol., 39(5):1331-1336, 2021.

SUMMARY: The objective of this study was to evaluate the role of the variations of carotid artery course on the relationship between styloid process (SP) and internal carotid artery (ICA). Carotid CT angiography scans of 170 patients were retrospectively evaluated. The variability of the course of ICA were classified. The length and medial angulation of the SP were measured on coronal 3D images. On axial images, the shortest distance between the bone edge of the SP and ICA were measured. The distance between SP and ICA among the course patterns of carotid artery were compared statistically. In the comparison of distances between SP and ICA with respect to the course of ICA, the difference between straight and curving ( $p<0.001)$ was statistically significant. Curving caused the separation of ICA and SP. The highest and the shortest distance was at the curving and coiling group, respectively. We found that SP-ICA distance has a positive and negative correlation with SP angle $(p<0.001)$ and SP length $(p<0.001)$, respectively. The course of ICA is one of the major determinants affecting the relationship of ICA and SP. The curving pattern of ICA has a tendency to increase the distance between SP and ICA.
\end{abstract}

KEY WORDS: Styloid process; Carotid artery; CT angiography; Aberration.

\section{INTRODUCTION}

Styloid process (SP), cornu minus of the hyoid bone and stylohyoid ligament form the stylohyoid complex (Basekim et al., 2005). Styloid process is a cartilaginous bone at the base of the temporal bone and a close relationship of SP with internal carotid artery (ICA) causes a clinically relevant condition. Calcification of stylohyoid complex and elongation of SP may give rise to Eagle syndrome which is generally divided into two common presentations called as classic Eagle syndrome and stylocarotid form (Sveinsson et al., 2013). The occurrence of symptoms is related with the distortion of adjacent anatomical structures by elongated SP. In the vascular or stylocarotid form of Eagle syndrome, SP is in contact with the extracranial segment of ICA (Sveinsson et al.). Impingement of internal or external carotid artery may cause pain along the distribution of the artery and headache or migraine by stimulation of the sympathetic nerve plexus associated with the artery (Chuang et al., 2007). Patients presenting with carotid dissections and neurological symptoms have been described (Faivre et al., 2009; Sveinsson et al.; Aydin et al., 2018).
Risk factors causing compression of carotid artery have been described in various studies. Elongation of SP, calcification of the stylohyoid complex, and narrowed SP angle are major factors for bony compression and the stylocarotid syndrome (Pokharel et al., 2013; Burulday et al., 2017; Eraslan et al., 2017). Variations of the course of carotid artery also have an important role on the relationship between ICA and SP. Getting closer of carotid artery with pharyngeal wall may lead hemorrhagic complications in surgical procedures of this region (Gossner et al., 2013). Therefore, various anatomical or angiographic studies have been reported to classify the variations of the course of carotid artery (Fazan et al., 2007; Gossner et al.; Zenteno et al., 2014). The classification described by Weibel \& Fields is the most accepted one in the literature. Kinking, coiling and elongation are the main titles of course variations of carotid artery in this classification (Weibel \& Fields, 1965a,b). It is well known that the prevalence increases with age (Gossner et al.). However, it is not clear whether the displacement of artery secondary to tortuosity decreases or increases the risk of ICA-SP contact. There are

\footnotetext{
${ }^{1}$ Department of Radiology, Mersin University, Faculty of Medicine, Mersin, Turkey.

${ }^{2}$ Department of Biostatistics and Medical Informatics, Mersin University, Faculty of Medicine, Mersin, Turkey.
} 
a few publications related to medial or lateral displacement of ICA at which the distance between the carotid artery and pharynx have been investigated (Lien et al., 2014; Pfeiffer et al., 2016). Herein, we aimed to evaluate the effect of carotid artery course variations on the relationship between ICA and SP at CT angiography (CTA) scans.

\section{MATERIAL AND METHOD}

Patient population. The carotid CTA scans of 280 consecutive patients between June 2016 and January 2017 were retrospectively evaluated. Carotid occlusions, carotid stents, vascular abnormalities such as carotid hypoplasia, carotid endarterectomies, inadequate examinations due to motion artifacts were excluded. A total of 170 patients were included after the exclusion.

Imaging protocol. A 64-slice CT scanner (Toshiba Aquilion 64, Toshiba Medical Systems, Tokyo, Japan) was used to obtain the CTA examinations. The bolus tracking technique was performed and scanning was initiated when the contrast attenuation in the aortic arch reached 100 Hounsfield units. Scanning range was from the ascending aorta to the vertex.

Measurements. The images were transferred to a dedicated workstation and after the reconstruction 3D images were obtained. All scans were evaluated by a single radiologist. The length of SP between the attachment point to the temporal bone and the tip was measured on coronal plane 3D images. The ossified stylohyoid ligament segment at the tip of SP was also added to the length of SP. The angle between

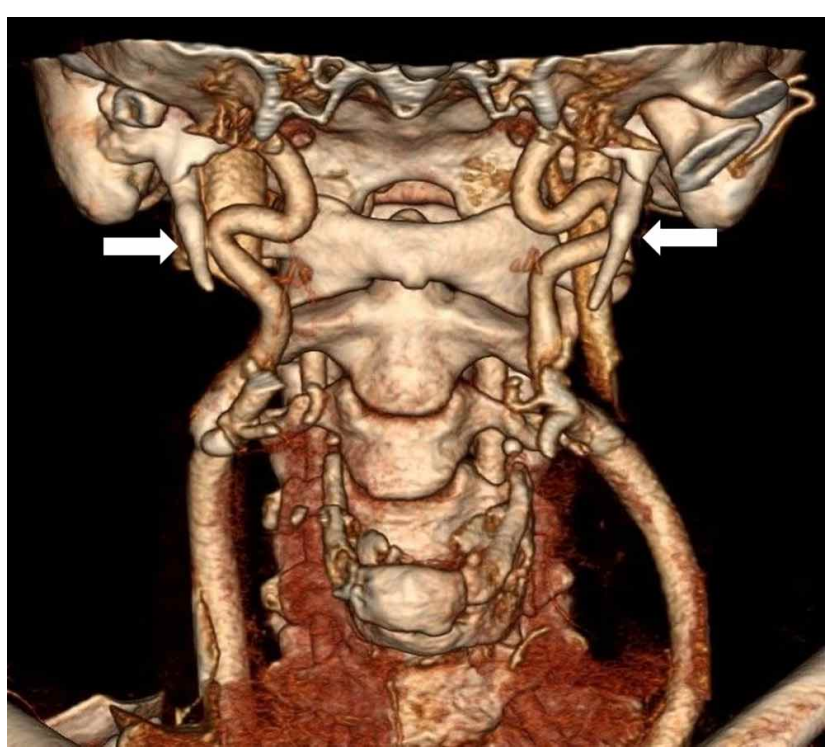

Fig. 1. Coronal 3D CT image shows the bilateral kinking of ICA. Note that ICAs are in touch with SP (arrows). the line connecting the base of the SPs and the axis of the SP was also measured on coronal plane 3D images as previously described in the literature (Basekim et al.).

It has been mentioned that the proximity of ICA and SP is present not only at the tip of the SP but also may occur among all the parts of SP (Fazan et al.; Eraslan et al.). Therefore, the shortest distance between the bone edge of the SP and the wall of ICA was measured on axial images.

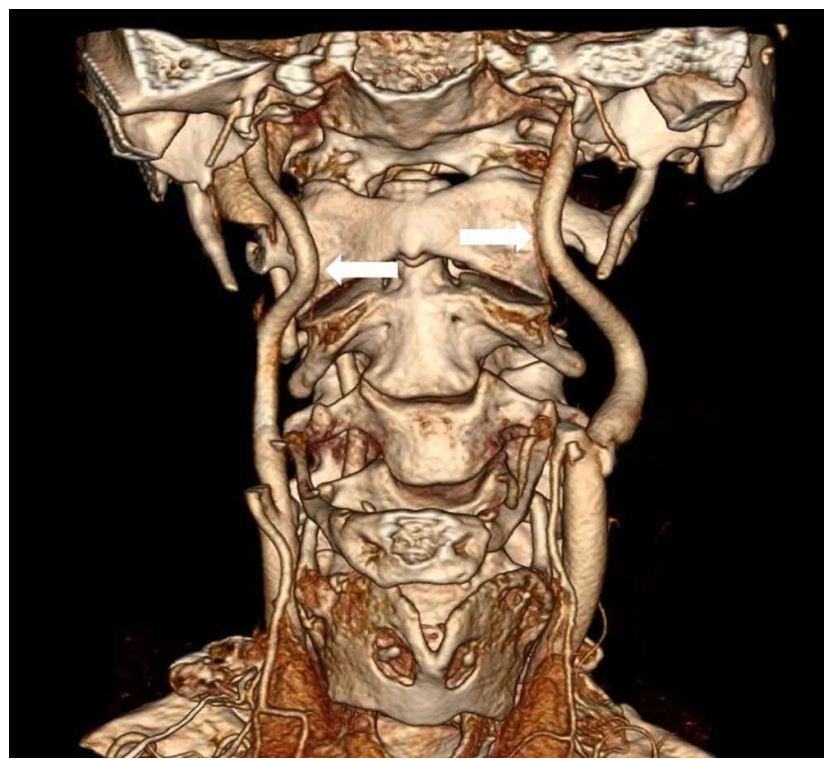

Fig. 2. Curving of bilateral ICAs on 3D CT image (arrows). Medialization of right ICA secondary to curving causes seperation of the artery and SP.

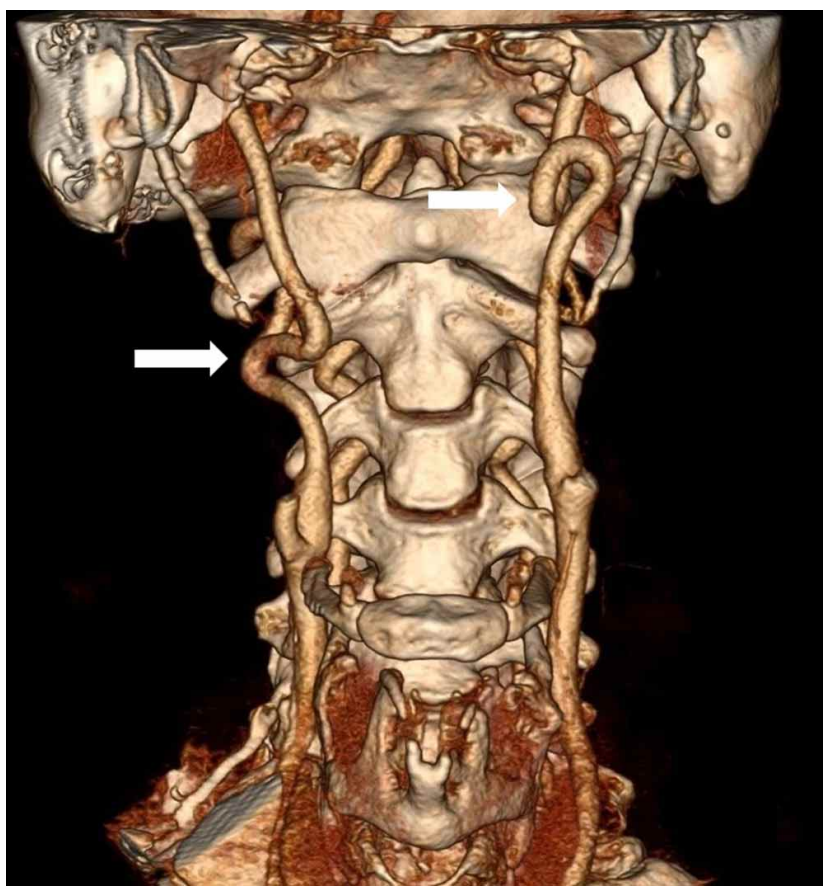

Fig. 3. Kinking of the right and coiling of the left ICAs at different levels on 3D CT image (arrows). 
The aberrant course of the cervical ICA was evaluated according to the classification defined in the literature. The course of the ICA was classified as straight without any curvature. Curving was elongation of the artery with a deflection angle of more than $90^{\circ}$ with displacement. Sharp bend of the vessel with a deflection angle of $<90^{\circ}$ was defined as kinking. A loop of $360^{\circ}$ was noted as coiling (Figs. 1 to 3 ) (Weibel \& Fields, 1965a,b; Paulsen et al., 2000; Pfeiffer et al.). The level of kinking and coiling was also noted as nasopharynx or oropharynx.

Statistical analysis. Normality controls for continuous measurements were tested with the Shapiro Wilk test. Paired Samples $t$ test was used for the differences between the right and left measurements of each parameter. Student $t$ test and variance analysis were used for the differences between groups. The Levene test was used for the homogeneity of the variances. When variance was homogenous One-way ANOVA was used and the Welch test was used when it was not homogenous. Bonferroni and Games Howell tests were used for multiple comparisons. Mean and standard deviation values were used as descriptive statistics. Relationships between continuous measurements were tested by Pearson correlation test. For statistical significance, $\mathrm{p}<0.05$ was taken.

The approval for the study was taken from Mersin University Ethical Committee of Clinical Researches.

\section{RESULTS}

A total of $76(44.7 \%)$ women and $94(55.3 \%)$ men were included in the study. The mean age of the patients was $60.7 \pm 14.5$. The mean age of the women and men was $61.4 \pm 15.5$ and $60.1 \pm 13.7$, respectively. When the sexes in terms of the mean age were compared, the difference was found to be statistically nonsignificant $(p=0.575)$.

The distribution of ICAs with respect to the course of the artery is shown in Table I.

Table I. The frequency of internal carotid artery course patterns.

\begin{tabular}{lc}
\hline & $\mathrm{N}(\%)$ \\
\hline Straight & $81(23.8)$ \\
Curving & $150(44.1)$ \\
Kinking & $88(25.9)$ \\
Coiling & $21(6.2)$ \\
\hline
\end{tabular}

Mean length of the right and left SP was measured as $26.1 \pm 7.9 \mathrm{~mm}$ (range 4.9-67.2 mm), 25.8 $\pm 7.2 \mathrm{~mm}$ (range 8$49.5 \mathrm{~mm}$ ), respectively (Table II).
Table II. The mean measurements of the right and left sides.

\begin{tabular}{llrc}
\hline & \multicolumn{1}{c}{ Right } & \multicolumn{1}{c}{ Left } & $\mathrm{p}$ \\
\hline SP Length & $26.12 \pm 7.97$ & $25.81 \pm 7.20$ & 0.436 \\
SP Angle & $69.96 \pm 5.15$ & $70.40 \pm 4.85$ & 0.229 \\
ICA-SP & $4.96 \pm 3.12$ & $4.99 \pm 2.83$ & 0.878 \\
\hline
\end{tabular}

SP: Styloid process, ICA: Internal carotid artery.

Mean medial angle of the right and left SP were measured as $69.9 \pm 5.1^{\circ}$ (range 56.7-85.9), $70.4 \pm 4.8^{\circ}$ (range $58.6 \pm 84.6)$, respectively.

The distance between SP and ICA showed positive and negative correlations with SP angle $(\mathrm{p}<0.001)$ and SP length $(\mathrm{p}<0.001)$, respectively (Table III). However, coiling causes disruption of this correlation (Table IV).

Table III. The relationship between ICA-SP distance and SP Angle/ Length.

\begin{tabular}{llll}
\hline & & SP Angle & SP Length \\
\cline { 3 - 4 } ICA-SP distance & $\mathrm{r}$ & 0.260 & -0.361 \\
& $\mathrm{p}$ & $<0.001$ & $<0.001$ \\
\hline
\end{tabular}

SP: Styloid process, ICA: Internal carotid artery.

Table IV. The relationship between ICA-SP distance and SP length/ angle with respect to ICA aberrations.

\begin{tabular}{llcccc}
\hline \multicolumn{5}{c}{ ICA-SP distance } \\
\hline \multirow{2}{*}{ SP length } & $\mathrm{r}$ & -0.545 & -0.430 & -0.100 & -0.153 \\
& $\mathrm{p}$ & $<\mathbf{0 . 0 0 1}$ & $<\mathbf{0 . 0 0 1}$ & 0.352 & 0.509 \\
\cline { 2 - 6 } SP angle & $\mathrm{r}$ & 0.385 & 0.168 & 0.348 & 0.143 \\
& $\mathrm{p}$ & $<\mathbf{0 . 0 0 1}$ & $\mathbf{0 . 0 4 0}$ & $\mathbf{0 . 0 0 1}$ & 0.537 \\
\hline
\end{tabular}

SP: Styloid process, ICA: Internal carotid artery.

Table V shows the classification of ICA-SP distance, SP length and SP angle with respect to the course of the artery.

The distance of ICA/SP between straight-curving $(\mathrm{p}<0.001)$, curving-kinking $(\mathrm{p}<0.001)$ and curving-coiling $(\mathrm{p}<0.001)$ was statistically significant.

The length of SP was statistically different between straight and curving group ( $\mathrm{p}=0.012)$. Therefore, for the parameter of ICA-SP distance, univariate analysis was performed from the general linear model, and the SP length parameter was included in the model as a random factor. In other words, after the effect of the SP length parameter was removed, the differences of ICA-SP distance between the groups of ICA course were examined again. Accordingly, the differences between straight and curving $(p<0.001)$, curving and kinking $(\mathrm{p}<0.001)$, curving and coiling $(\mathrm{p}=$ 0.002 ) were found to be statistically significant. 
ESEN, K.; BALCI, Y.; OZGUR, A.; ERDOGAN, S. \& TEN, B. Effect of internal carotid artery aberrations on the distance between styloid process and carotid artery. Int. J. Morphol., 39(5):1331-1336, 2021.

Table V. The classification of the mean ICA-SP distance, SP length and SP angle with respect to the course of the artery.

\begin{tabular}{lccccc}
\hline & Straight $(\mathrm{N}=81)$ & Curving $(\mathrm{N}=150)$ & $\begin{array}{c}\text { Kinking } \\
(\mathrm{N}=88)\end{array}$ & $\begin{array}{c}\text { Coiling } \\
(\mathrm{N}=21)\end{array}$ & $\mathrm{p}$ \\
\hline SP Length & $28,18 \pm 7,65$ & $24,96 \pm 7.42^{*}$ & $25,23 \pm 7.29$ & $27.77 \pm 8,18$ & $\mathbf{0 , 0 0 9}$ \\
SP Angle & $69.74 \pm 5.30$ & $70.60 \pm 4,93$ & $70.00 \pm 5,07$ & $69.69 \pm 3,92$ & 0,577 \\
ICA-SP Distance & $4,20 \pm 2,13$ & $6,13 \pm 3,23^{*}$ & $3,99 \pm 2,70^{\dagger}$ & $3,81 \pm 2.04^{\dagger}$ & $<\mathbf{0 , 0 0 1}$ \\
\hline
\end{tabular}

*: Differences with straight $\uparrow$ : Differences with curving $\ddagger$ :Differences with kinking. SP: Styloid process, ICA: Internal carotid artery

\section{DISCUSSION}

The stylocarotid form of Eagle syndrome occurs secondary to the compression of carotid artery by the elongated SP or calcified stylohyoid ligament. Therefore, evaluating the relationship of SP and ICA gains a critical importance in the diagnosis of the disease. Computed tomography angiography is the most appropriate imaging modality that provides assessment of the distance between two structures in different planes and evaluation of accompanying abnormalities or variations. The SP is a fixed bony structure adjacent to the carotid artery (Raser et al., 2011). The risk factors affecting the SP-ICA relationship related with bony component have been reported in the literature. Aberrant course of cervical ICA has been denoted another risk factor for the contact between SP and ICA. It has been mentioned that the factors except the length of SP are probably rendered insignificant by the variability of cervical ICA (Muthusami et al., 2013). The role of the aberrant course of ICA has not been well-defined and no definitive relationship has been reported in the literature. Nevertheless, due to the diversity of arterial variations it seems feasible to establish a relationship between the course variations and SP-ICA distance. Various descriptions have been defined to classify the ICA aberrations in the literature. We used the classification system at which course of ICA were divided to four groups as straight, curving, kinking and coiling. The difference between the straight and curving group was statistically significant in the comparison of patterns of ICA course with respect to the ICA-SP distance and curving caused separation of ICA and SP. However, kinking and coiling did not have any significant effect on ICA-SP distance.

Proximity of ICAs to the pharynx secondary to aberrations causes a clinical relevance. In the study reported by Pfeiffer $e t$ al., the $91.8 \%$ of aberrant ICAs show medial displacement. It was also mentioned that the vessel's minimal distance to the pharyngeal wall does not correlate with anatomic classification and on average, this distance was similar for vessels with tortuosity/kinking and larger for vessels with coiling. Lien et al. reported that most of the ICA aberrations are medial deviations and the increased severity of nasopharyngeal ICA aberrancy did not shorten the distances between the ICA and nasopharyngeal subsites. The shortest distance between ICA and nasopharyngeal wall was found in the curving group in the same study (Lien et al.). In this context, our results are consistent with the findings of Pfeiffer et al. and Lien et al. Curving or elongation of ICA may be accepted as a negative risk factor for the contact of ICA and SP. However, this study evaluated only the relationship between SP and ICA via the distance between two structures. On the other hand, it is well-known that a closer relationship or a contact may not cause stylocarotid syndrome.

An elongated SP, abnormal angulation of SP and shorter distance between SP and ICA have been pointed out as risk factors for cervical carotid artery dissection and stylocarotid artery syndrome (Chuang et al.; Raser et al.; Muthusami et al.; Renard et al., 2013; Eraslan et al.; Amorim et al., 2018). Although the role of elongation is commonly accepted, it was claimed that longer SP might indirectly represent a closer proximity to the carotid artery (Renard $e t$ $a l$.) and the appearance of the stylocarotid artery syndrome is not dependent merely on the existence of an elongated SP which may occur even with a SP of normal length (Chuang et al.; Renard et al.; Eraslan et al.). Furthermore, the role of either medial or lateral angulation is controversial. Thus, there are various reports related with the length and angulation of SP in carotid artery dissection and Eagle Syndrome. Burulday et al., reported that decrease in the coronal plane angle of SP in Eagle syndrome patients is more strongly related to increased symptoms than the length of the SP. In the study reported by Yavuz et al. (2008) the anterior angulation and the length of the SP have been reported as responsible for the symptoms of Eagle's Syndrome. Raser et al. did not demonstrate an association between SP angulation and dissection. Mathusami et al., did not find any association between angulation of SP and increased risk for carotid artery dissection and also mentioned that contact between the SP and ICA is facilitated by a long SP (Mathusami et al., 2013). In the present study, there was a positive correlation between SP angle and SP-ICA distance. The correlation was negative between SP length and SPICA distance. Coiling was the only pattern that both of the correlations were not detected. 
The etiology of ICA variations is controversial whether they are congenital or acquired (Fazan et al.). It has been mentioned that combination of embryological maldevelopment and age-related degenerative changes in the vessel may play role in producing carotid abnormalities (Pfeiffer et al.). However, coiling of the internal carotid artery may be due to embryological causes, elongation and kinking may be related with atherosclerosis or fibromuscular dysplasia (Schenk et al., 1996). Kinking is more frequently associated with cerebrovascular disease and the altered fluid dynamics produced by kinks may lead to degenerative changes more frequently in the vessel wall (Paulsen et al.). In the present study, the prevalence of curving, kinking and coiling were $44.1 \%, 25.9 \%$ and $6.2 \%$ respectively. Nevertheless, compared with the literature the ratio of aberration was higher and curving was the most frequent in our study group. However, the mean age of our study population was also higher (60.7) and almost all of the CTAs were performed with suspicion of stenosis secondary to atherosclerosis. Therefore, it may not be correct to compare our data of prevalence reported for general population in the literature.

The occurring of major abnormalities of the cervical segment of ICA near of its origin or at level of the atlas/axis and the rarely exceeding of SP $4 \mathrm{~cm}$ in length (C1-C2 level) suggest us that the level of the variations may also be effective (Weibel \& Fields, 1965a,b; Zenteno et al.; Pfeiffer et al.). Pfeiffer et al. reported that coiling was found close to the skull base in $42.9 \%$ of vessels. Therefore, we also classified the level of kinking or coiling as oropharynx or nasopharynx. The distance between ICA and SP did not differ between two levels $(\mathrm{p}=0.602)$. Curving was not always suitable to classify with respect to the level mentioned above because of unclear boundaries.

In conclusion, we hypothesized that medialization or lateralization of the artery secondary to aberrationsmay be crucial in determining the distance between SP and ICA. Unfortunately, kinking and coiling did not demonstrate a statistically significant effect on SP-ICA distance. However, in the presence of ICA elongation, an increasing distance between SP and ICA was demonstrated. This result was consistent with the findings of studies emphasizing the medial displacement of artery secondary to curving or elongation. To the best of our knowledge, this is the first report investigating the effect of ICA aberrations on the distance between ICA and SP. Our findings suggest that, not only the length or angulation of SP but also the curving of ICA, may be a prominent factor in determining the relationship between ICA and SP.
ESEN, K.; BALCI, Y.; OZGUR, A.; ERDOGAN, S. \& TEN, B. Efecto de las variaciones de la arteria carótida interna en la distancia entre el proceso estiloides y la arteria carótida. Int. J. Morphol., 39(5):1331-1336, 2021.

RESUMEN: El objetivo de este estudio fue evaluar el rol de las variaciones que tiene el curso de la arteria carótida en la relación entre el proceso estiloides (PE) y la arteria carótida interna (ACI). Se evaluaron retrospectivamente angiografías por tomografía computarizada carotídea de 170 pacientes. Se clasificó la variabilidad del curso de ACI. Se midieron en imágenes coronales y en 3D la longitud y la angulación medial del PE. En las imágenes axiales, se midió la distancia más corta entre el margen del PE y la ACI. Se comparó estadísticamente la distancia entre PE y la ACI entre los patrones de trayecto de la arteria carótida. La comparación de las distancias entre PE y la ACI respecto al curso de ACI, fue estadísticamente significativa, siendo la diferencia entre arterias recta y curva $(p<0,001)$. La arteria curva provocó la separación de la ACI y del PE. Las mayores y menores distancias estaban en el grupo de arterias curvas y enrolladas, respectivamente. La distancia PE-ACI tiene una correlación positiva y negativa con el ángulo PE ( $\mathrm{p}<0,001)$ y la longitud del $\mathrm{PE}(\mathrm{p}<0,001)$, respectivamente. El curso de la arteria carótida interna es uno de los principales determinantes que afectan la relación con el proceso estiloides. El patrón de curva de la ACI tiende a aumentar la distancia entre PE y la propia arteria arteria.

PALABRAS Clave: Proceso estiloides; Arteria carótida; Angiografía por TC; Aberración.

\section{REFERENCES}

Amorim, J. M.; Pereira, D.; Rodrigues, M. G.; Beato-Coelho, J.; Lopes, M.; Cunha, A.; Figueiredo, S.; Mendes-Pinto, M.; Ferreira, C.; Sargento-Freitas, J.; et al. Anatomical characteristics of the styloid process in internal carotid artery dissection: Case-control study. Int J. Stroke, 13(4):400-45, 2018.

Aydin, E.; Quliyev, H.; Cinar, C.; Bozkaya, H. \& Oran, I. Eagle syndrome presenting with neurological symptoms. Turk. Neurosurg., 28(2):21925,2018

Basekim, C. C.; Mutlu, H.; Güngör, A.; Silit, E.; Pekkafali, Z.; Kutlay, M.; Colak, A.; Oztürk, E. \& Kizilkaya, E. Evaluation of styloid process by three-dimensional computed tomography. Eur. Radiol., 15(1):1349, 2005.

Burulday, V.; Akgül, M. H.; Muluk, N. B.; Yagdiran, B. \& Inal, M. The importance of medial-lateral styloid process angulation/coronal plane angle in symptomatic eagle syndrome. Clin. Anat., 30(4):487-91, 2017.

Chuang, W. C.; Short, J. H.; McKinney, A. M.; Anker, L.; Knoll, B. \& McKinney, Z. J. Reversible left hemispheric ischemia secondary to carotid compression in Eagle syndrome: surgical and CT angiographic correlation. AJNR Am. J. Neuroradiol., 28(1):143-5, 2007.

Eraslan, C.; Ozer, M. A.; Govsa, F.; Alagoz, A. K. \& Calli, C. Relationship of stylohyoid chain and cervical internal carotid artery detected by 3D angiography. Surg. Radiol. Anat., 39(8):897-904, 2017.

Faivre, A.; Abdelfettah, Z.; Rodriquez, S. \& Nicoli, F. Neurological picture. Bilateral internal carotid artery dissection due to elongated styloid process and shaking dancing. J. Neurol. Neurosurg. Psychiatry, 80(10):1154-5, 2009. 
Fazan, V. P. S.; Ribeiro, R. A.; Oliveira, M. A. S.; Caetano, A. G. \& Rodrigues Filho, O. A. Tortuosity of the internal carotid artery cervical course: case reports and literature review. Braz. J. Morphol. Sci., 24(4):244-7, 2007.

Gossner, J.; Manka, R. \& Larsen, J. Aberrations of the cervical carotid artery which may be dangerous in pharyngeal surgery-A computed tomographic study. Adv. Comput. Tomogr., 2(1):29-33, 2013.

Lien, C. F.; Weng, H. H.; Lin, B. S.; Liu, C. F.; Wu, T. C. \& Lin, Y. S. Effect of carotid artery aberrancy on the distance between the vessel and nasopharyngeal subsites. J. Chin. Med. Assoc., 77(5):253-7, 2014.

Muthusami, P.; Kesavadas, C.; Sylaja, P. N.; Thomas, B.; Harsha, K. J. \& Kapilamoorthy, T. R. Implicating the long styloid process in cervical carotid artery dissection. Neuroradiology, 55(7):861-7, 2013.

Paulsen, F.; Tillmann, B.; Christofides, C.; Richter, W. \& Koebke, J. Curving and looping of the internal carotid artery in relation to the pharynx: frequency, embryology and clinical implications. J. Anat., 197(Pt. 3):373-81, 2000.

Pfeiffer, J.; Becker, C. \& Ridder, G. J. Aberrant extracranial internal carotid arteries: New insights, implications, and demand for a clinical grading system. Head Neck, 38 Suppl. 1:E687-93, 2016.

Pokharel, M.; Karki, S.; Shrestha, I.; Shrestha, B. L.; Khanal, K. \& Amatya, R. C. Clinicoradiologic evaluation of Eagle's syndrome and its management. Kathmandu Univ. Med. J. KUMJ, 11(44):305-9, 2013.

Raser, J. M.; Mullen, M. T.; Kasner, S. E.; Cucchiara, B. L. \& Messé, S. R. Cervical carotid artery dissection is associated with styloid process length. Neurology, 77(23):2061-6, 2011.

Renard, D.; Azakri, S.; Arquizan, C.; Swinnen, B.; Labauge, P. \& Thijs, V. Styloid and hyoid bone proximity is a risk factor for cervical carotid artery dissection. Stroke, 44(9):2475-9, 2013.

Schenk, P.; Temmel, A.; Trattnig, S. \& Kainberger, F. Current aspects in diagnosis and therapy of carotid artery kinking. HNO, 44(4):178-85, 1996.

Sveinsson, O.; Kostulas, N. \& Herrman, L. Internal carotid dissection caused by an elongated styloid process (Eagle syndrome). BMJ Case Rep., 2013:bcr2013009878, 2013.

Weibel, J. \& Fields, W. S. Tortuosity, coiling, and kinking of the internal carotid artery. I. Etiology and radiographic anatomy. Neurology, 15:7$18,1965 \mathrm{a}$.

Weibel, J. \& Fields, W. S. Tortuosity, coiling, and kinking of the internal carotid artery. II. Relationship of morphological variation to cerebrovascular insufficiency. Neurology, 15:462-8, 1965b.

Yavuz, H.; Caylakli, F.; Yildirim, T. \& Ozluoglu, L. N. Angulation of the styloid process in Eagle's syndrome. Eur. Arch. Otorhinolaryngol., 265(11):1393-6, 2008

Zenteno, M.; Vinuela, F.; Moscote-Salazar, L. M.; Alvis-Miranda, H.; Zavaleta, R.; Flores, A.; Rojas, A. \& Lee, A. Clinical implications of internal carotid artery tortuosity, kinking and coiling: a systematic review. Rom. Neurosurg., 21(1):50-9, 2014.
Corresponding author:

Kaan Esen

Mersin University

Faculty of Medicine, Department of Radiology

Cadde, Yenisehir-MERSIN 33110

Mersin

TURKEY

E-mail: kaanessen@yahoo.com

$\begin{array}{ll}\text { Kaan Esen } & \text { : ORCID ID:0000-0002-8404-7484 } \\ \text { Yüksel Balci } & \text { : ORCID ID:0000-0003-1758-9600 } \\ \text { Anıl Özgür } & \text { : ORCID ID:0000-0003-4463-1923 } \\ \text { Semra Erdogan } & \text { : ORCID ID:0000-0003-2935-0760 } \\ \text { Barıs Ten } & \text { : ORCID ID:0000-0001-6536-2780 }\end{array}$

Received: 06-04-2021

Accepted: 28-06-2021 